Requirements for applying Evidence-Based Social Group Work as a strategy to boost the Professional Performance of Social Workers engaging with Patient Groups

Mohamed M. Soliman Mahmoud Assistance Professor of Social Group Work

Social Work Faculty - Assiut University 
مجلة كلية الخدمة الاجتماعية للار اسات و البحوث الاجتماعية - جامعة كـ 


\title{
Requirements for applying Evidence-Based Social Group Work as a strategy to boost the Professional Performance of Social Workers engaging with Patient Groups
}

\begin{abstract}
:
This study aimed to determine Requirements for applying Evidence-based social group work as a strategy to boost the Professional Performance of Social Workers engaging with Patient Groups Given this, a combination of analytical descriptive studies and a comprehensive social survey methodology was applied to a sample of (87) social workers. Based on the questionnaires applied, a set of significant results were inferred. First, cognitive requirements are knowledge related to advanced group work method, skill requirements are the ability to apply EB group work steps, the ethical requirements are the requirement of keeping the information pertaining to patients and their families confidential, and barriers are lack of training courses meant to develop EB group work, and suggestions are conducting several training courses on evidence-based social group work is seen Key Words: Requirements, Professional Performance, Evidence Based Social Group Work (EBSGW).
\end{abstract}


متطلبات استخدام الممارسة المرتكزة على الادلة في طريقة العمل مع الجماعات كاستراتيجية لتدعيم

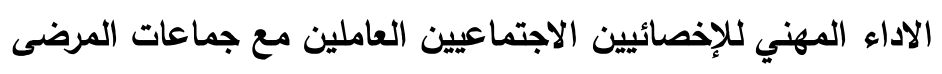

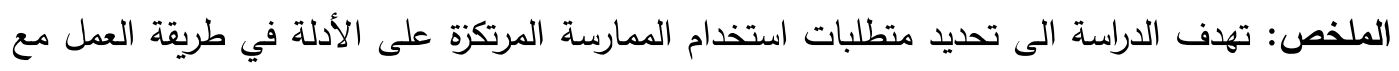

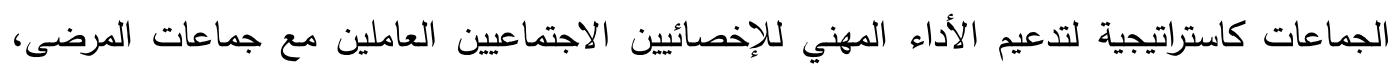
لذلك تم استخدام نمط الدراسات الوصفية التحليلية ومنهج المسح الاجتماعي الثامل لعينة قوامها (87)

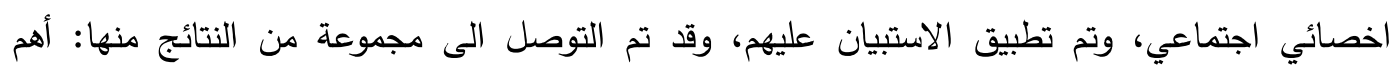

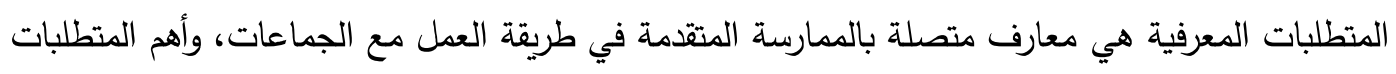
المهارية هي القدرة على تطبيق مراحل الممارسة المرتكزة على الادلة في طريقة العمل مع الجماعات، وأهم المتطلبات القيمية هي الالتزام بسرية المعلومات الخاصة بالمرضى وأسرهم. وأهم المعوقات التي تواجه الأخصائيين الاجتماعيين هي عدم وجود دورات تدريبية لتتمية الممارسة المرتكزة على الادلة في طريقة

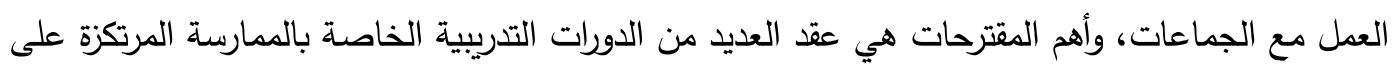

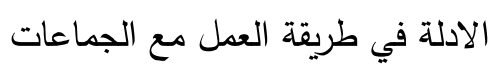
الكلمات المفتاحية: المتطلبات، الأداء المهني، طريقة العمل مع الجماعات المرتكزة على الادلة. 


\section{Study Problem.}

Human development it is the process that emphasizes a human-being and aims to develop his skills and potentials so that he can self-reliantly attain a proper standard of living. Noticeably, the recent trends in human and social sciences played a key role in the introduction of the human development concept. (Kumar, 2013, 5)

Social Work as a profession derives a wide range of its scientific and professional knowledge and theories from other disciplines and professions. This evidently fosters its development course and establishes a related comprehensive knowledge base which helps meet the profession objectives: standardizing its sciences, fulfilling clients' satisfaction, and promoting knowledge and skills for practitioners and specialists, which contributes to the development of the profession. (Gibson \& Yuill, 2017, 11)

Moreover, the social work profession, given its various approaches included among its several settings, targets at developing its practice methods and techniques by means of introducing the most highly competent professional interventions. This can be seen in the earliest literature written on the profession which focused on how significant it is to provide a perfectly standardized professional practice. Hence, the scientific approach has been adopted as the major methodology that practitioners believe would result in real evidence-based interventions. (Connolly \& Harms, 2014, 9)

Responsively, a relevant study (Gitterman, 2013) stressed that the social work profession, either as a science or as an art, is meant to adopt evidence-based practice as an alternative approach to typical one. Further, it is required to define a set of professional knowledge and skills that are compatible with the values and ethics of the profession.

The practice of social work in the medical setting is a prominent area where the best possible assistance and decisions for therapeutic and social services can be provided to patients. Besides, it provides patients' primary needs and helps them address their disease-related difficulties.

And, Medical social workers are responsible for offering the support and resources that patients need in order to fully recover from a medical illness or injury as well as the resulting emotional, physical, or psychological concerns. After performing a comprehensive assessment of a patient's support needs, they work with the patient's family, support system, and other health service providers to coordinate an individualized discharge plan for in-home medical equipment, transportation, counseling, or other follow-up treatments. (Karen \& William, 2016, 83)

Another study (Frederiksen, 2019) demonstrated the need to train medical social workers in evidence-based practice in terms of fully identifying techniques and application methods at their workplaces, e.g. hospitals.

Medical social workers complete psychological assessment, develop discharge plans, arrange home care services, provide appropriate referrals, offering support groups, and advocating for patients and their families. However, since medical social workers work with patients with ranging medical situations 
from traumatic sexual assault to terminal cancer diagnosis, their duties tend to change according to each patient's individual needs. In serious cases of child abuse or violence, medical social workers may also be responsible for providing psycho-social support, grief counseling, and assisting law enforcement in their investigations.( Dziegielewski, 2004, 102)

Relatedly, the National Association of Social Workers (NASW, 2003) highlighted the need to address evidence-based practice with respect to all settings. More, it recommended that social workers should identify, improve, standardize, avail and apply the best available evidence to tackle the issues clients' groups may undergo. In addition, it emphasizes considering practitioners' practice wisdom or professional experience when applying evidence. (NASW, 2003)

Study (Spensberger, 2019) emphasized the need to educate social workers about evidence-based practice in social work through various training courses. He also stressed applying the model phases in all professional settings of social work.

Study (Adam, 2009) spotlighted the efficacy of applying evidencebased practice in social work settings: juvenile Care, drug abuse, old-age, and health care, following a model designed for specific types of evidence commensurate with the nature of each setting.

Evidence-based practice, empirically supported interventions (also called empirically informed interventions and evidence-based practices), and practice guidelines are terms that are frequently, although inappropriately, interchangeably used (Rubin \& Parrish, 2009).

Another study conducted by (Jeffrey, \& Matthew, 2013) indicated that evidence-based practice involves a set of specific steps that help social workers identify, select, and implement effective client interventions.

And, Group work is an essential component of social work practice and an established effective treatment modality for psychosocial problems, personal growth, and social skills development (Goodrich, 2008).

Study (Lietz, 2007) demonstrated the role group work plays in determining the strengths and weaknesses of client groups. Thereby, this helps a group worker develop a model geared towards backing strengths and addressing weaknesses in a professional and scientific manner.

Since the break of the 2000 s, a variety of modern models and methods have been introduced, including evidence-based practice in group work. These emphasize the importance of preparing practitioners who are able to make appropriate decisions related to professional intervention with groups in terms of actual results based on experimental research. Accordingly, this can reduce bias and result in an effective practice which takes into account practitioners 'experience and skills when providing professional services.

Given the deficiency of stereotypical professional intervention efforts with diverse client groups, group work methodology tended to utilize evidence-based practice model. Proportionally, a set of actual assessments of group work approach was implemented, and more precise and effective tools for professional intervention with groups were put into action. Hence, EB group work-related approaches, publications, and research came on the scene. 
Study (Drumm, 2006) elaborated that group work methodology can be looked upon as effective as it defines a peculiar conceptual framework and bases a set of basic skills, according to which EB group work model is built and regarded as an integral part of the method itself.

Study (Quinn \& Shera, 2009) in a relevant study, showed that evidencebased practice group work is originally based on both therapeutic approaches and practice techniques.

Additionally, since evidence-based practice group work is absolutely crucial when assessing research feasibility - given the constant increase in various approaches and models - practitioners have tended to standardize the tools used for professional intervention. Consequently, costs can be cut down, relapses of client groups can be avoided, and more positive results can be reached.

Study (Hyde, 2013) emphasized the value of considering mutual aid as an essential technique in EB group work, for including a set of characteristics a group worker may wish to have, namely participation, cooperation, responsibility and leadership.

The professional preparation of medical social workers who engage in evidence-based practice necessitates that they should have many requirements that they need to master and train in so as to be able to handle different patient and treatment groups.

Study (Weller, 2015) pointed out that group workers, functioning in EB group work, are indeed meant to adhere to four major constituents: research, experience, personal views, and a group member's perspective.

Study (Pollio, 2008) introduced a set of steps for evidence processing that a group worker can undertake: assessing the evidence gathered, acquiring knowledge drawn from reading academic journals, evaluating practice results, applying models by practitioners, and deciphering the effect of individual differences.

Nonetheless, the use of this approach of practice in the medical setting requires enhancing the professional performance of a group worker as to knowledge, skills and values. Examples of such cognitive requirements may involve identifying a range of points: evidence-based practice definition, EB group work management steps, different evidence types, adequate evidence application techniques, decision-making concerning proper evidence, and followup techniques of practice steps (Macgowan. 2008, 40).

Study (Gitterman, 2014) also defined a set of cognitive requirements which he assumed as pivotal in comprehending the modern scientific methodology of professional practice. He supposed this can be done through identifying the knowledge related to the nature of clients in terms of the profession.

Study (Macgowan, 2006) indicated the availability of an evidence database on group work and stressed evidence-based practice and steps for applying such a model to practitioners.

Requirements skills, a variety of requirements were listed. According to Polio, these skill requirements include formulating hypotheses and converting information into questions, critically analyzing reached research evidence, 
extracting research results, communicating and exchanging data, analyzing academic research, and investigating the most appropriate evidence for professional intervention with patient groups (Pollio, 2008, 21).

In a later study, (Macgowan, 2012) listed the evidence-based practice model among a set of cognitive criteria essential to group social work practice. Additionally, he identified a number of skills which practitioners ought to have in various settings.

Requirements ethics, Terry stated a range of considerations a social worker should possess. Among these are: to be unbiased towards a specific view, to decide on therapeutic methods in accordance with a patient's situation, to be acquainted with how to perfectly utilize personal experience in professional interventions with clients, to realize individual differences among patient groups, to commit to a full degree of confidentiality for handled patients (individuals or groups), to consider cultural diversity among patient groups, and to regard applied methodology and processional ethics. (Terry, 2015)

Study (Gumpert \& Black, 2006) stressed the necessity of providing a great deal of ethical professional knowledge to group workers applying the evidencebased social group work model so that the problems related to group diversity can be addressed.

In all, the above requirements can be achieved through providing a group worker with a persistent professional preparation and updated knowledge, whether via periodicals, seminars, training courses or academic research. In this way, a group worker is able to keep pace with the latest developments and promote the level of professional practice, which is seen as the profession top goal. Given this, it is apparent how important and beneficial evidence-based social group work is in reaching the best reliable and validated evidence that can best fit patient groups. As shown in the above paragraphs, a wide range of studies have a consensus that social workers need baseline requirements (cognitive, skill and ethical) to be qualified enough to successfully engage in evidence-based social group work with patients. Hence, the study problem can be formulated in the following question: What are the requirements social workers should have to apply evidence-based social group work as a strategy to boost their professional performance with patient groups?

\section{Study Importance:}

The study in hand is meant to emphasize the following points:

1- Development requires the preparation of resourceful human energies with plenty of knowledge and skills in order to cope with the scientific and intellectual revolution.

2- Social work is basically interested in achieving professional development in all of its settings.

3- Among social work settings, the medical one is the most important as it requires providing professional preparation for social workers functioning in it.

4- The evidence-based social group work model is a key basis for the professional growth of social workers working with patient groups. 
5- The need for developing the professional practice of group work along with social workers engaging in the medical setting and patient groups.

6- Social workers wishing to improve the quality and efficiency of human services will find help in research evidence.

Study Aims:

The study aims to verify a major goal, which is to determine the requirements social workers should have to apply evidence-based social group work as a strategy to boost their professional performance with patient groups. A set of sub-objectives can be listed under this goal; namely,

1- Determining knowledge requirements social workers should have to apply evidence-based social group work.

2- Determining skills requirements social workers should have to apply evidence-based social group work.

3- Determining ethical requirements social workers should have to apply evidence-based social group work.

4- Determining barriers that confront social workers concerning the application of evidence-based social group work with patient groups.

5- Determining proposals that enable social workers to apply evidence-based social group work with patient groups.

\section{Study Questions:}

The study targets at answering the following key question: what are the requirements social workers should have to apply evidence-based social group work as a strategy to boost their professional performance with patient groups? This question can be divided into a set of sub-questions as follows:

1- What are the knowledge requirements social workers should have to apply evidence-based social group work?

2- What are the skills requirements social workers should have to apply evidence-based social group work?

3- What are the ethical requirements social workers should have to apply evidence-based social group work?

4- What are the barriers that confront social workers concerning the application of evidence-based social group work with patient groups?

5- What are the proposals that enable social workers to apply evidence-based social group work with patient groups?

\section{Study Concepts:}

\section{1- Requirement Concept:}

The study emphasizes the concept 'requirement' which is linguistically defined as something required, wanted, needed or essential to the occurrence of something else (Dictionary Webster, 2004, 993).

According to Oxford Dictionary, it is something required, must be available, or that has frequently been found essential. Also, it is a condition in pursuit of certain results (Oxford, 1993, 732).

Similarly, Haywood defined it as the mass of knowledge that an individual should have in order to be able to perform their roles efficiently and effectively (Haywood, 2019,105).

In specific, requirements can be operationally categorized into: 
- Cognitive requirements for applying evidence-based social group work with patient groups.

- Skill requirements for applying evidence-based social group work with patient groups.

- Ethical requirements for applying evidence-based social group work with patient groups.

2- Evidence-based social group work (EBGW) Concept:

Evidence-based practice (EBP) is an approach that aims to improve the process through which high-quality scientific research evidence can be obtained and translated into the best practical decisions to improve practice.( (Houser, \&Oman, 2011, 54)

Drisko and Grady (2012) defined Evidence-based practice (EBP) is an integrative decision making process aimed at improving client outcomes and effectiveness in social work practice.( Drisko, \& Grady, 2012, 34)

Sackett et al (1996) defined as the conscientious, explicit, and judicious use of current best evidence in making decisions about the care of individual patients. (Sackett et al., 1996, p. 71)

And Gambrill (2007), McNeill (2006) defined evidence-based practice as integrating empirically-validated treatments and clinical expertise, combined with elements of critical thinking and client needs (Gambrill, 2007; McNeill, 2006, 447-462).

EBGW, which is defined as "a process of the judicious and skillful application in group work of the best evidence, based on research merit, impact, and applicability, using evaluation to ensure desired results are achieved" (Macgowan, 2008, 3).

Evidence refers to "unobserved as well as observed phenomena if the former reflects signs or indications that support, substantiate, or prove their existence, accuracy, or truth" (Cournoyer, 2004, p. 3).

Evidence-based social group work is operationally defined as the ability of a group worker to apply evidence-based social group work steps, relying on the knowledge, skills, and ethics of modern practice so that he can identify the best evidence suitable to patient groups.

\section{3- Professional performance Concept:}

Heyman, \& Congress (2018) Professional performance is defined as the ability of a social worker to handle professional work units to develop their competences to solve problems encountering them and meet their various needs. (Heyman, \& Congress, 2018, 79)

Dorfman (1996) defined as part of the ongoing processes, related to professional practice, that require reviewing what has been accomplished compared to assigned professional duties. (Dorfman, 1996, 64)

Worsley (2013), More, it indicates the ability of a social worker to undertake job tasks according to their efficiency and the extent of appropriateness of conditions that affect work environment.(Worsley, 2013)

Operationally, professional performance is, in terms of the study in hand, defined as the ability of a social worker to address patient groups using the best 
evidence regarding group work, knowledge, skills, and ethics related to evidencebased social group work.

Theoretical Structure of the Study:

Evidence-based social group work (EBSGW) and developing professional performance for social workers working with patient groups.

The term evidence-based practice is rooted in medicine's effort to provide the best medical care to patients (Straus, Richardson, Glasziou, \& Haynes, 2005). EBP was originally conceived in the healthcare field and emphasized the use of the best current research results in making clinical decisions for individual patients and wider health policy decisions for communities. Ultimately it was an approach to decision-making in which the clinician uses the best evidence available, in consultation with the patient, to decide upon the option that suits the patient best (Gray, 2001).

EBP movement has permeated the helping professions in the past decade, resulting in enthusiasm for utilizing the EBP process as a framework for improving the integration of research into the practice setting. There are many reasons to be optimistic about this model. First, there has been a substantial increase in practice-related research in the past two decades, much of which has been summarized in systematic reviews and meta-analyses. Second, more advanced technology and widespread access to the Internet have made access to practice resources and research available in real time. Finally, the EBP model is more pragmatic and better operationalized when compared to past efforts (e.g., the empirical practice movement) as it accounts for complex issues when using research to make practice decisions. Specifically, the EBP process model acknowledges the importance of both clinical expertise and client characteristics/ values, along with the consideration of the best available evidence when making practice decisions.( Tabachnick, \& Fidell, 2007, 115).

In the United States, EBP in social work is in its early stages. Some recent publications describe its possibilities, advocate for standards, and suggest cautions. From my analysis and reflections on the nature of social work practice, I conclude that EBP in social work rests on four cornerstones: (1) research and theory; (2) practice wisdom, or what we and other professionals have learned from our clients, which also includes professional values; (3) the person of the practitioner, or our personal assumptions, values, biases, and world views; and (4) what clients bring to practice situations.( Jane, 2005, 52-61).

EBP is typically described as involving six steps (Gibbs, 2003; Sackett et al., 2000; Straus et al., 2005). In the real practice world, however, these steps may not be pursued in the following order.

1- Convert information needs into an answerable question. An initial assessment of the client must be done to determine what questions are important. The assessment should be used as a basis for a well-formulated question that must be not only answerable but also phrased in a way that a search of existing research literature can be conducted to answer this question. The question can be about assessment, description, prevention, or intervention.

2- Track down the best evidence to answer the question. 
3- Critically appraise the evidence for its validity (closeness to the truth), impact (size of the effect), and applicability usefulness in practice).

4- Integrate the critical appraisal with practice experience and client's strengths, values, and circumstances.

5- Evaluate effectiveness and efficiency in exercising Steps 1 to 4 and seek ways to improve on them next time.

6- Teach others to follow the same process.

Previously, we have described five broad strategies for dissemination and implementation of EBP:

(a) the teaching model, (b) direct implementation, (c) a model combining evidence and stakeholder consensus, (d) combining staff training and organizational development, and (e) development of professional infrastructure as agent (Straus, S. E., Richardson, W. S., Glasziou, P., \& Haynes, R. B. 2005).

And, the following principles for implementing EBP into practice. EBP-based practitioners need to:

- Be able to explain the EBP clearly, including an ability to deconstruct key elements as a corrective experience to previous failed implementation efforts.

- Be able to create an evaluation that yields useful outcome data for the practitioner and the client and that is realistic given the characteristics of the client system.

- Be able to re choose and refine intervention and evaluation efforts, based on increased knowledge of the client system and as their willingness to participate changes.

- Be aware of relevant evidence about specific techniques, incorporate evidence developed as part of the intervention, and be critical consumers of both types of evidence in specific situations with clients and client systems.( Rosen, 2003, 208)

Today there are many terms representing EBP, which can be organized into three types: empirically supported group interventions; evidence-supported group processes, techniques, and guidelines; and EBGW, which critically incorporates the other two areas. This section reviews these three areas and notes how they connect with group work:

\section{1- Empirically supported group interventions (ESGIs)}

Empirically supported group interventions (ESGIs) have been shown to be efficacious for specific diagnostic groups (often using the DSM-IV) through randomized clinical trials (RCTs), meta-analyses, or through consensus of experts based on a critical review of the best research evidence. The term intervention is used broadly to include preventive interventions designed to prevent problems for at-risk populations.

\section{2- Evidence-Supported Group Processes, Techniques, and Guidelines}

Group workers in health care should also become aware of evidence-supported group processes, techniques, and guidelines endorsed through rigorous research and/or expert consensus. Two examples in this area include cohesion and practice standards. 
a) Cohesion. One important area explored in the literature is the evidence-based psychotherapy relationship (Norcross \& Lambert, 2011). Cohesion is "the therapeutic relationship in group psychotherapy emerging from the aggregate of member-leader, member-member, and member-group relationships" (Norcross, \& Lambert, 2011, 8)

b) Practice Standards and Guidelines. Group workers in health care should also be aware of group work standards and practice guidelines, which have been developed by panels of experts to promote appropriate and effective practices. These standards and guidelines are rooted in professional values and codes of ethics of the respective professional organizations that developed them, such as the American.(Norcross, \& Lambert, 2011, 104)

\section{3- Evidence-based social group work (Process Model)}

The third type of EBP is a process model, evidence-based group processes and guidelines, or other relevant and appropriate evidence with the highest possible rigor.

Evidence-based social group work comprises appraising systematically, collected evidence from a variety of sources, evaluating the outcomes of practice, implementing models of practice consistently, attending to individual differences in practice decisions and incorporating evidence in understanding group process, leadership, and development (Macgowan, 2012, 582). Practitioners who subscribe to evidence-based social group work must maintain currency about research, learn about new models, carefully consider the rationale for treatment decisions, evaluate their own practice, and report results from their experiences in group work practice journals.

An evidence-based social group work approach involves an ongoing, critical review of research literature to determine what information is credible, and what policies and practices would be most effective given the best available evidence. It also involves rigorous quality assurance and evaluation to ensure that evidence-based practices are replicated with fidelity, and that new practices are evaluated to determine their effectiveness. (Macgowan, \& Hanbidge, 2014, 309)

The ASGW has developed multicultural and social justice competence principles for group workers (ASGW, 2012). The principles fall into the following three main areas: (1) awareness of self and group members; (2) use of strategies and skills that reflect multicultural and social justice advocacy competence in group planning, performing, and processing; and (3) social justice advocacy. In working with increasingly culturally diverse populations, it is essential for group workers in health care to become familiar with these guidelines.(ASGW,2012, 320)

Group work is an attractive treatment choice in part because it may be more economical than individual counseling and psychotherapy. However, the complexity of working with multiple members while harnessing and using several levels of systemic development challenges counselors in attempts to increase the effectiveness of their work in groups.(Corey, 2008, 67)

Social workers, as a professional group, have an ethical obligation to provide interventions to consumers with known effectiveness and to minimize the possibility of unintended harm . . . Additionally social workers need to respond to 
society's demand for greater accountability and transparency . . . or accept the potential marginalization of the profession.

(Smith \& Harnek \& Hayward, 2007, 481).

The EBSGW model has four stages in which group workers (a) formulate an answerable question derived from the practice context; (b) search for evidence; (c) undertake a critical review of the evidence to identify the best available evidence; and (d) apply the evidence with judgment, skill, and concern for relevance and appropriateness for the group, utilizing evaluation to determine if desired outcomes are achieved.

Stage one: Begin with a practice question. A member-relevant, answerable, practice question (MAP) related to the group service is identified. Examples of MAP questions might be, "What is the briefest yet most effective group intervention for reducing depression among group members?" and "How can I increase cohesion among my group members?" Once the question is formulated and refined, then it is suitable for a search.

Stage two: Search for evidence. The second stage is to undertake a search for evidence, expanding beyond one's convenient evidence (e.g., one's own experience or one's own possibly outdated library) and to systematically collect and appraise evidence. Searches should focus on research-based evidence rather than authoritative-based evidence.

Stage three: Critically review to identify "Best Available" evidence. The third stage involves a critical review of the evidence, yielding the best available evidence. The evidence (e.g., article, book, material) must be evaluated for its rigor, impact, and applicability.

First, workers evaluate the rigor (research merit) of the evidence. Studies high in rigor minimize bias. In intervention research, the preference is for research evidence, which increases the confidence that the intervention was specifically responsible for beneficial effects, as opposed to evidence that is authority-based. The degree of confidence that an intervention or action will produce a desired outcome may be assessed using a "'hierarchy of evidence,' with each level yielding a higher comfort level of certainty, from the most basic level of anecdotal or word-of-mouth testimonials to the highest level of scientific study, the controlled clinical trial with random assignment of subjects" (Bond, 2004, 45). However, both sets of evidence, whether authority or research-based, should be evaluated for rigor.

Second, group workers also evaluate the impact of the evidence; that is, how significant (i.e., statistically and clinically) and in what direction are the results. Ideally, there should be clinically meaningful change.

In the applicability stage, group workers evaluate the evidence's relevance and appropriateness for their own groups for "clinical utility" or "clinical applicability." To evaluate applicability, the fit of the material with the clinical situation in three areas is assessed: agency setting (e.g., will the agency support the practice?), group worker (e.g., is the group worker qualified to do it?), and group members (e.g., does the material fit with group member values and preferences?). 
The three areas of rigor, impact, and applicability map well onto the nine "ideal features" of a health care intervention in hospital described by Bond, Drake, and Becker (2010): (a) demonstrate effectiveness through rigorous research studies, (b) few side effects, (c) positive long-term outcomes, (d) welldefined for replication by the group worker, (e) reflect client goals and preferences for service, (f) consistent with societal goals, (g) reasonable costs, (h) relatively easy to implement, and (i) adaptable to diverse communities and client. To evaluate rigor, impact, and applicability of evidence, group workers use a set of guides designed for group work. (Bond, Drake, \& Becker, 2010, 280-290)

Stage four: Apply (replicate, adapt) the evidence and evaluate. This stage involves application of the evidence, which may involve replication or adaptation, and to evaluate if desired outcomes are achieved. As applied to EBGW, implementation is the integration of the best available evidence into group work. As a general guide, group workers should maintain the integrity of the original intervention/technique.(Regehr, Stern, \& Shlonsky, 2007, 409)

\section{Methodological Procedures of the Study:}

\section{1- Study Type:}

This study pursues the descriptive and analytical methods that aim to determine the characteristics of a particular phenomenon and the factors affecting or resulting from it. Within the context of the current study, it is meant to define the requirements social workers need for the application of evidence-based social group work with patient groups .

\section{2- Method:}

This study adopts the social survey methodology, namely a complete enumeration method applied to social workers engaging in Assiut hospitals.

\section{3- Study Tools:}

In pursuit of data collection, the researcher designed a questionnaire to specify the requirements social workers need to apply evidence-based social group work with patient groups. The questionnaire, applied to social workers functioning in all hospitals in Assiut Governorate, was built according to the following steps:

\section{A) Collecting and drafting the questionnaire questions:}

1- Reviewing literature on evidence-based social group work.

2- Surveying both Arab and foreign research related to evidence-based social group work, and making use of its own tools such as questionnaires and scales in conformity with the study tool.

B) Governance:

1- A group of (9) reviewers, engaging in all social work settings in general and group work in particular, assessed the questionnaire.

2- The researcher amended the questionnaire form according to the reviewers' recommendations regarding omission, amendment or addition of the questions, in pursuit of face validity.

3- Later, the researcher calculated the percentage of the inter-rater agreement on the questionnaire questions. Worth considering, phrases with an agreement degree less than $80 \%$ were excluded, applying Cooper formula: 


$$
\mathrm{P}=\frac{N P}{N P+N N P} \times 100
$$

As a result, the questionnaire meant for working social workers comprises (5) axes, each of which has a set of indicators. Proportionally, the form was eventually printed to be field-applied (Cooper, 2009, 26).

4- Study Fields:

A) Human Field:

(87) Social Workers, representing all social staff working in Assiut hospitals.

B) Place Field:

All hospitals in Assiut Governorate, numbering 9.

C) Time Field:

Data collection lasted from $5-9-2020$ to $8-10-2020$.

\section{Results:}

In this part, the results related to the characteristics of the research population, including social workers engaging with patient groups are viewed, analyzed, and discussed.

Table (1) Demographic characteristics of the participants. $(N=87)$

\begin{tabular}{|c|c|c|c|c|}
\hline No & Variable & Categories & Frequency & Percentage \\
\hline \multirow{4}{*}{1} & \multirow{4}{*}{ Age } & Less than 30 years & 4 & $\% 4.60$ \\
\hline & & 30 - to less than 35 years & 9 & $\% 10.34$ \\
\hline & & 35 - to less than 40 years & 41 & $\% 47.13$ \\
\hline & & 40 years and More than & 33 & $\% 37.93$ \\
\hline \multicolumn{3}{|r|}{ Total } & 87 & $\% 100$ \\
\hline \multicolumn{3}{|r|}{ Mean } & \multicolumn{2}{|c|}{38.90} \\
\hline \multicolumn{3}{|c|}{ Standard deviation } & \multicolumn{2}{|c|}{5.845} \\
\hline \multirow{2}{*}{2} & \multirow{2}{*}{ Gender } & Male & 65 & $\% 74.71$ \\
\hline & & Female & 22 & $\% 25.29$ \\
\hline \multicolumn{3}{|r|}{ Total } & 87 & $\% 100$ \\
\hline \multirow{3}{*}{3} & \multirow{3}{*}{ Qualification } & BS in Social Work & 39 & $\% 44.83$ \\
\hline & & BS in Sociology & 8 & $\% 9.20$ \\
\hline & & Post-Graduate Studies & 40 & $\% 45.97$ \\
\hline \multicolumn{3}{|r|}{ Total } & 87 & $\% 100$ \\
\hline \multirow{4}{*}{4} & \multirow{4}{*}{$\begin{array}{c}\text { Years of } \\
\text { experience }\end{array}$} & Less than 5 years & 9 & $\% 10.34$ \\
\hline & & $5-10$ years & 42 & $\% 48.28$ \\
\hline & & 10 to less than 15 years & 22 & $\% 25.29$ \\
\hline & & 15 to more years & 14 & $\% 16.09$ \\
\hline \multicolumn{3}{|r|}{ Total } & 87 & $\% 100$ \\
\hline \multicolumn{3}{|r|}{ Mean } & \multicolumn{2}{|c|}{9.26} \\
\hline \multicolumn{3}{|c|}{ Standard deviation } & \multicolumn{2}{|c|}{3.877} \\
\hline
\end{tabular}


Based on table (1), it is shown that the age variable mean is $\mathrm{M}=(38.90)$ whereas the standard deviation is $\sigma=(5.845)$. Social workers from 35 - to less than 40 years are represented by $(47.13 \%)$, while those of ages between 40 and more years constitute $(37.93 \%)$. Conversely, the percentage of workers between 30 - to less than 35 years amounts $(10.34 \%)$, compared to that of workers under 30 $(4.60 \%)$. Noticeably, it is evident that most of the study sample are males by (74.71\%), while females form $(25.29 \%)$.

Concerning degrees, workers with post-graduate studies in social work constitute $(45.97 \%)$, while those who have a BA in Social Work form $(44.83 \%)$. In comparison, workers with a BA in Sociology represent (9.20\%).

In addition, the same table indicates that the mean of experience year's variable is $M=(9.26)$ and the standard deviation is $\sigma=(3.877)$. In detail, the table data show that the percentage of workers between 5 and less than 10 experience years amounts (48.28\%), compared to $(25.29 \%)$ for those between 10 and less than 15. More, workers between 15 and more experience years is (16.09\%), while finally, those who have less than 5 experience years constitute $(10.34 \%)$.

Table (2): Cognitive Requirements for Evidence-based social group work. $(\mathrm{N}=87)$

\begin{tabular}{|c|l|c|c|c|c|c|c|}
\hline No & $\begin{array}{l}\text { Cognitive requirements for evidence- } \\
\text { based social group work }\end{array}$ & Yes & Often & No & Total & Mean & Rank \\
\hline 1 & $\begin{array}{l}\text { Knowledge related to the nature of } \\
\text { evidence-based social group work }\end{array}$ & 60 & 20 & 7 & 227 & 2.61 & 8 \\
\hline 2 & $\begin{array}{l}\text { Knowledge related to evidence-based } \\
\text { social group work steps }\end{array}$ & 67 & 17 & 3 & 238 & 2.74 & 6 \\
\hline 3 & $\begin{array}{l}\text { Knowledge related to evidence type } \\
\text { used in the medical setting }\end{array}$ & 68 & 19 & 0 & 242 & 2.78 & 4 \\
\hline 4 & $\begin{array}{l}\text { Knowledge related to how literature } \\
\text { can be used in field practice of the } \\
\text { medical setting }\end{array}$ & 55 & 11 & 21 & 208 & 2.39 & 11 \\
\hline 5 & $\begin{array}{l}\text { Knowledge related to advanced group } \\
\text { work method }\end{array}$ & 81 & 6 & 0 & 255 & 2.93 & 1 \\
\hline 6 & $\begin{array}{l}\text { Knowledge related to the problems } \\
\text { patient groups undergo }\end{array}$ & 47 & 31 & 9 & 212 & 2.44 & 9 \\
\hline 7 & $\begin{array}{l}\text { Knowledge related to making proper } \\
\text { decisions about determining evidence } \\
\text { suitable to patients }\end{array}$ & 70 & 13 & 4 & 240 & 2.76 & 5 \\
\hline 8 & $\begin{array}{l}\text { Knowledge related to handling patient } \\
\text { groups in terms of evidence-based } \\
\text { social group work }\end{array}$ & 65 & 18 & 4 & 235 & 2.70 & 7 \\
\hline 9 & $\begin{array}{l}\text { Knowledge related to advanced } \\
\text { professional practice methods } \\
\text { concerning patient groups }\end{array}$ & 63 & 22 & 2 & 235 & 2.70 & 7 (Rep) \\
\hline 10 & $\begin{array}{l}\text { Knowledge related to the application of } \\
\text { technologies to communicate with } \\
\text { patient groups }\end{array}$ & 73 & 14 & 0 & 247 & 2.84 & 2 \\
\hline 11 & $\begin{array}{l}\text { Knowledge related to the difficulties in } \\
\text { fnow }\end{array}$ & 51 & 20 & 16 & 209 & 2.40 & 10 \\
\hline
\end{tabular}




\begin{tabular}{|c|l|c|c|c|c|c|c|}
\hline & applying adequate evidence to patients & & & & & & \\
\hline 12 & $\begin{array}{l}\text { Knowledge related to assessing } \\
\text { evidence-based social group work }\end{array}$ & 75 & 9 & 3 & 246 & 2.83 & 3 \\
\hline Total & $\mathbf{7 7 5}$ & $\mathbf{2 0 0}$ & $\mathbf{6 9}$ & $\mathbf{2 . 7 9 4}$ & & \\
\hline Overall mean & $\mathbf{6 4 . 5 8}$ & $\mathbf{1 6 . 6 7}$ & $\mathbf{5 . 7 5}$ & & & $\mathbf{8 7}$ \\
\hline Overall percentage & $\mathbf{7 4 . 2 3}$ & $\mathbf{1 9 . 1 6}$ & $\mathbf{6 . 6 1}$ & & & $\% 100$ \\
\hline Relative strength & $\mathbf{\% 8 9 . 3 2}$ & \\
\hline
\end{tabular}

Extrapolating the data in table 2, it is obvious that the cognitive requirements for evidence-based social group work constitute a relative strength of $(89.32 \%)$. In terms of ranking, knowledge related to advanced group work method comes first with a weighted mean of (2.93), while that related to the application of technologies to communicate with patient groups follows in second place with a weighted mean of (2.84). In the third rank resides knowledge related to how to assess evidence-based social group work with a weighted weight of (2.83), compared to that related to how literature can be used in field practice in the medical setting with a weighted mean of (2.39) in last place. This may imply the disinclination of group workers to indulge in conceptual knowledge and its application to patient groups. Rather, they are likely to benefit from the practical reality in applying this practice to take advantage of recent approaches in serving patient groups.

These results are consistent with the studies of Brettle (2020), Wike et al (2014), and Pandya (2010), in which they stressed the necessity of meeting EBP cognitive requirements included in this model: knowledge of the model itself, the nature of the evidence used, evidence application, and the creation of an appropriate environment for implementing this model. Further, they assumed that social workers are meant to practice evidence-based practice through developing a set of scales that determine the evidence used and practice implementation phases.

Table (3): Skill Requirements for Evidence-based social group work. ( $N=87$ )

\begin{tabular}{|c|l|c|c|c|c|c|c|}
\hline No & $\begin{array}{l}\text { Skill requirements for evidence-based } \\
\text { social group work }\end{array}$ & Yes & $\begin{array}{c}\text { Ofte } \\
\mathbf{n}\end{array}$ & No & Total & Mean & Rank \\
\hline 1 & Ability to apply EB group work steps & 69 & 13 & 5 & 238 & 2.74 & 1 \\
\hline 2 & $\begin{array}{l}\text { Ability to determine evidence needed by } \\
\text { patient groups }\end{array}$ & 65 & 18 & 4 & 235 & 2.70 & 2 \\
\hline 3 & $\begin{array}{l}\text { Ability to take advantage of work team to } \\
\text { attain the best results for patient groups }\end{array}$ & 37 & 29 & 21 & 190 & 2.18 & 10 \\
\hline 4 & $\begin{array}{l}\text { Ability to utilize research when dealing } \\
\text { with patients }\end{array}$ & 49 & 30 & 8 & 215 & 2.47 & 6 \\
\hline 5 & $\begin{array}{l}\text { Ability to scientifically solve patients' } \\
\text { various problems }\end{array}$ & 44 & 19 & 24 & 194 & 2.23 & 9 \\
\hline 6 & $\begin{array}{l}\text { Ability to search for evidence that best } \\
\text { fits patients' problems }\end{array}$ & 50 & 26 & 11 & 213 & 2.45 & 7 \\
\hline 7 & $\begin{array}{l}\text { Ability to classify evidence so that it can } \\
\text { be reliable when addressing patient } \\
\text { groups }\end{array}$ & 62 & 21 & 4 & 232 & 2.67 & 4 \\
\hline
\end{tabular}




\begin{tabular}{|c|c|c|c|c|c|c|c|}
\hline 8 & $\begin{array}{l}\text { Ability to utilize hospitals resources for a } \\
\text { better patient care }\end{array}$ & 38 & 17 & 32 & 180 & 2.07 & 11 \\
\hline 9 & $\begin{array}{l}\text { Ability to access to the best evidence } \\
\text { suitable to patient groups }\end{array}$ & 58 & 24 & 5 & 227 & 2.61 & 5 \\
\hline 10 & Ability to properly handle group work & 62 & 22 & 3 & 233 & 2.68 & 3 \\
\hline 11 & $\begin{array}{l}\text { Ability to assess the outputs of } \\
\text { professional intervention with patient } \\
\text { groups }\end{array}$ & 47 & 24 & 16 & 205 & 2.36 & 8 \\
\hline 12 & $\begin{array}{l}\text { Ability to follow-up group work outputs } \\
\text { using recent scientific techniques }\end{array}$ & 40 & 27 & 20 & 194 & 2.23 & 9 (Rep) \\
\hline & Total & 621 & 270 & 153 & 2.556 & & \\
\hline & Overall mean & 51.75 & 22.5 & 12.75 & & & 87 \\
\hline & Overall percentage & 59.48 & 25.86 & 14.66 & & & $\% 100$ \\
\hline & Relative strength & \multicolumn{6}{|c|}{$\% 82.14$} \\
\hline
\end{tabular}

Based on table (3), skill requirements for evidence-based social group work constitute a relative strength of $(82.14 \%)$. Noticeably, the ability to apply EB group work steps comes first with a weighted mean of (2.74), while the ability to determine evidence needed by patient groups ranks second with a weighted mean of (2.70). Third in rank, the ability to properly handle group work is represented by a weighted mean of (2.68). In comparison, the ability to utilize hospitals resources for a better patient care ranks last with a weighted mean of (2.07). Proportionally, this may function as a strong indicator of group workers' tendency to make the most of hospital resources in providing high-quality services for patient groups, reaching the best results, and attaining professional development for group workers who engage with patient groups.

Obviously, these results are in accordance with the research of both Macgowan (2012) and Daniel (2011) who highlighted the significance of evidence-based practice in creating a skill structure for social workers working with client groups or, generally, practicing group work, including the evidencebased practice model. Furthermore, they outlined a set of skills that practitioners should possess in various areas: formulating hypotheses and converting information into questions, conducting critical assessments of the evidence obtained, extracting research results, applying communication and exchange of information, analyzing research, and researching the evidence consistent with each individual case. 
Table (4): Ethical Requirements for Evidence-based social group work. ( $N=$ 87)

\begin{tabular}{|c|c|c|c|c|c|c|c|}
\hline No & $\begin{array}{c}\text { Ethical requirements for evidence- } \\
\text { based social group work }\end{array}$ & Yes & Often & No & Total & Mean & Rank \\
\hline 1 & $\begin{array}{l}\text { Adhering to evidence-based social group } \\
\text { work requirements when handling } \\
\text { patients }\end{array}$ & 78 & 6 & 3 & 249 & 2.86 & 2 \\
\hline 2 & $\begin{array}{l}\text { Keeping the information pertaining to } \\
\text { patients and their families confidential }\end{array}$ & 87 & 0 & 0 & 261 & 3 & 1 \\
\hline 3 & $\begin{array}{l}\text { Social workers' commitment to a proper } \\
\text { standard of practice when handling } \\
\text { patients }\end{array}$ & 79 & 4 & 4 & 249 & 2.86 & $\begin{array}{c}2 \\
(\text { Rep) }\end{array}$ \\
\hline 4 & 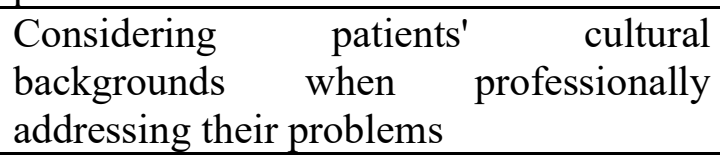 & 43 & 31 & 13 & 204 & 2.34 & 8 \\
\hline 5 & $\begin{array}{l}\text { Considering the use of therapeutic } \\
\text { methods that match patient groups }\end{array}$ & 38 & 29 & 20 & 192 & 2.21 & 9 \\
\hline 6 & $\begin{array}{l}\text { Making professional relationships with } \\
\text { patient groups during professional } \\
\text { intervention periods }\end{array}$ & 59 & 28 & 0 & 233 & 2.68 & 4 \\
\hline 7 & $\begin{array}{l}\text { Committing to the profession's ethics } \\
\text { when intervening with patient groups }\end{array}$ & 67 & 20 & 0 & 241 & 2.77 & 3 \\
\hline 8 & $\begin{array}{l}\text { Committing to providing a perfect health } \\
\text { care to patients who receive medication }\end{array}$ & 57 & 30 & 0 & 231 & 2.66 & 5 \\
\hline 9 & Being unbiased when handling patients & 34 & 49 & 4 & 204 & 2.34 & 8 \\
\hline 10 & $\begin{array}{l}\text { Emphasizing the value of collaboration } \\
\text { with the hospital staff to provide patients } \\
\text { with several services }\end{array}$ & 46 & 34 & 7 & 213 & 2.45 & 7 \\
\hline 11 & $\begin{array}{l}\text { Paying due attention to individual } \\
\text { differences among handled patients }\end{array}$ & 29 & 45 & 13 & 190 & 2.18 & 10 \\
\hline 12 & $\begin{array}{l}\text { Considering patients' rights which are } \\
\text { consistent with health issues they } \\
\text { undergo }\end{array}$ & 46 & 37 & 4 & 216 & 2.48 & 6 \\
\hline & Total & 663 & 313 & 68 & 2.683 & & \\
\hline & Overall mean & 55.25 & 26.08 & 5.67 & & & 87 \\
\hline & Overall percentage & 63.51 & 29.98 & 6.51 & & & $\% 100$ \\
\hline & Relative strength & \multicolumn{6}{|c|}{$\% 85.67$} \\
\hline
\end{tabular}

Elaborating the date shown in table (4), the ethical requirements for evidencebased social group work constitute a relative strength of $(85.67 \%)$. Notably, the requirement of keeping the information pertaining to patients and their families confidential ranks first with a weighted mean of (3), whereas adhering to evidence-based social group work requirements when handling patients in association with social workers' commitment to a proper standard of practice when handling patients come second with a weighted mean of (2.86). Committing 
to the profession's ethics when intervening with patient groups and paying due attention to individual differences among handled patients rank third and last with weighted means of (2.77) and (2.18) respectively. This indicates to what extent objectivity has been reached concerning obtaining the best evidence matching patients' problems, applying research results credibly, achieving justice and equality, and taking into account the individual differences among patients.

Relevantly, these results are in agreement with the study of Craig et al (2020), in which they stressed the significance of raising group workers' awareness of the profession's ethics that everyone must adhere to, for it determines what is required to be done and how to perform it and defines all ethical responsibilities and duties, including committing to objectivity when handling patients. What is more, it specifies the professional values required to apply the evidence-based social group work model: considering individual differences, respecting a client's privacy, or applying confidentiality concerning everything related to the patient.

Table No. (5): The Barriers social workers encounter concerning applying Evidence-based social group work. ( $N=87)$

\begin{tabular}{|c|c|c|c|c|c|c|c|}
\hline No & $\begin{array}{l}\text { The barriers social workers encounter } \\
\text { concerning applying evidence-based } \\
\text { social group work to patient groups }\end{array}$ & Yes & $\begin{array}{c}\text { Ofte } \\
\text { n }\end{array}$ & No & Total & Mean & Rank \\
\hline 1 & $\begin{array}{l}\text { Lack of professional awareness of the } \\
\text { nature of applying EB group work }\end{array}$ & 72 & 12 & 3 & 243 & 2.79 & 3 \\
\hline 2 & $\begin{array}{l}\text { Lack of training courses meant to } \\
\text { develop EB group work }\end{array}$ & 81 & 4 & 2 & 253 & 2.91 & 1 \\
\hline 3 & $\begin{array}{l}\text { Excessive administrative burdens social } \\
\text { workers go through, which hinders } \\
\text { performing professional duties }\end{array}$ & 69 & 3 & 15 & 228 & 2.62 & 7 \\
\hline 4 & $\begin{array}{l}\text { Social workers lack sufficient knowledge } \\
\text { of modern technology }\end{array}$ & 66 & 13 & 8 & 232 & 2.67 & 6 \\
\hline 5 & Not enough social workers at hospitals & 70 & 6 & 11 & 233 & 2.68 & 5 \\
\hline 6 & $\begin{array}{l}\text { Some social workers' inclination to adopt } \\
\text { stereotypical methods in professional practice }\end{array}$ & 57 & 9 & 21 & 210 & 2.41 & 9 \\
\hline 7 & $\begin{array}{l}\text { Deficient utilization of developed skills } \\
\text { with patients in hospitals }\end{array}$ & 49 & 31 & 7 & 216 & 2.48 & 8 \\
\hline 8 & $\begin{array}{l}\text { Insufficient physical capabilities in } \\
\text { hospitals accommodating social workers }\end{array}$ & 78 & 6 & 3 & 249 & 2.86 & 2 \\
\hline 9 & $\begin{array}{l}\text { Social workers are unable to make } \\
\text { decisions about patients and their } \\
\text { pathological statuses. }\end{array}$ & 74 & 6 & 7 & 241 & 2.77 & 4 \\
\hline & Total & 616 & 90 & 77 & 2.105 & & \\
\hline & Overall mean & 68.44 & 10 & 8.56 & & & 87 \\
\hline & Overall percentage & 78.67 & 11.49 & 9.84 & & & $\% 100$ \\
\hline & Relative strength & \multicolumn{6}{|c|}{$\% 90.19$} \\
\hline
\end{tabular}

Given table (5), it is apparent that the barriers social workers encounter concerning applying evidence-based social group work to patient groups constitute a relative strength of $(90.19 \%)$. In light of ranking, lack of training courses meant to develop EB group work comes first with a weighted mean of (3), 
while insufficient physical capabilities in hospitals accommodating social workers is second with a weighted mean of (2.86). Respectively, lack of professional awareness of the nature of applying EB group work and social workers' inclination to adopt stereotypical methods in professional practice rank third and last with weighted means of (2.79) and (2.41). This may imply that some group workers still rely basically on standard practice, or in other words, do not keep pace with modern trends in their work fields. Hence, it is essential to conduct specialized training courses geared towards presenting realistic models and successful experiences which reflect the efficacy of this practice.

In concert with these results, Christ (2011) and McGuire (2006) indicated, in relevant studies, that the application of evidence-based social group work by researchers could be interrupted by several hindrances, e.g., insufficient time, lack of pursuit of introducing new ideas, counting on usual practices, variety of implementation places, nature of the client groups' problems, and knowledge deficiencies of group workers.

Table (6): Suggestions that enable social workers to apply Evidence-based social group work with patient groups: $(N=87)$

\begin{tabular}{|c|l|c|c|c|c|c|c|}
\hline No & $\begin{array}{l}\text { Suggestions that enable social workers } \\
\text { to apply evidence-based social group } \\
\text { work with patient groups }\end{array}$ & Yes & Often & No & Total & Mean & Rank \\
\hline 1 & $\begin{array}{l}\text { Providing a number of professional social } \\
\text { workers trained in applying evidence- } \\
\text { based social group work. }\end{array}$ & 69 & 12 & 6 & 237 & 2.72 & 4 \\
\hline 2 & $\begin{array}{l}\text { Committing to proper practice of group } \\
\text { work. }\end{array}$ & 59 & 25 & 3 & 230 & 2.64 & 5 \\
\hline 3 & $\begin{array}{l}\text { Increasing the number of social workers } \\
\text { who can multitask at hospitals. }\end{array}$ & 44 & 30 & 13 & 205 & 2.36 & 7 \\
\hline 4 & $\begin{array}{l}\text { Limiting administrative work load } \\
\text { carried out by social workers at hospitals. }\end{array}$ & 60 & 19 & 8 & 226 & 2.60 & 6 \\
\hline 5 & $\begin{array}{l}\text { Exchanging diverse experiences of EB } \\
\text { group work. }\end{array}$ & 74 & 11 & 2 & 246 & 2.83 & 3 \\
\hline 6 & $\begin{array}{l}\text { Providing logistic support for social } \\
\text { workers at hospitals. }\end{array}$ & 78 & 7 & 2 & 250 & 2.87 & 2 \\
\hline 7 & $\begin{array}{l}\text { Conducting several training courses on } \\
\text { evidence-based social group work. }\end{array}$ & 82 & 5 & 0 & 256 & 2.94 & 1 \\
\hline 8 & $\begin{array}{l}\text { Making partnerships between hospitals } \\
\text { and majored research centers to benefit } \\
\text { from their expertise. }\end{array}$ & 45 & 28 & 14 & 205 & 2.36 & 7 \\
\hline 9 & $\begin{array}{l}\text { Emphasizing the need for applying } \\
\text { evidence-based social group work. }\end{array}$ & 65 & 20 & 2 & 237 & 2.72 & $\begin{array}{c}\text { (Rep) } \\
\text { (Rep) }\end{array}$ \\
\hline 10 & $\begin{array}{l}\text { Stressing the significance of teamwork in } \\
\text { providing the best welfare to patient } \\
\text { groups. }\end{array}$ & 30 & 44 & 13 & 191 & 2.20 & 9 \\
\hline 11 & $\begin{array}{l}\text { Providing professional support at various } \\
\text { levels to assist social workers. }\end{array}$ & 34 & 37 & 16 & 192 & 2.21 & 8 \\
\hline & \begin{tabular}{l} 
T40 \\
\hline
\end{tabular}
\end{tabular}




\begin{tabular}{|c|c|c|c|c|c|c|}
\hline Overall mean & 58.18 & 21.64 & 7.18 & & & 87 \\
\hline Overall percentage & 66.87 & 24.88 & 8.25 & & & $\% 100$ \\
\hline Relative strength & \multicolumn{6}{|c|}{$\% 86.43$} \\
\hline
\end{tabular}

According to table (6), the relative strength of the suggestions that enable social workers to apply evidence-based social group work with patient groups is represented by a $(86.43 \%)$. In detail, conducting several training courses on evidence-based social group work is seen in first place with a weighted mean of (2.94), compared to providing logistic support for social workers at hospitals which ranks second with a weighted mean of (2.87). Exchanging diverse experiences of EB group work and stressing the significance of teamwork in providing the best welfare to patient groups rank third and last with weighted means of (2.83) and (2.20) respectively. This may imply that some group workers still rely basically on standard practice, or in other words, do not keep pace with modern trends in their work fields. Based on these figures, it can be inferred that there is a must to provide financial support meant for conducting training sessions for group workers on EB group work and to emphasize the importance of applying this trendy practice by working groups in order to provide the best assistance to patient groups.

These values were found to be in line with the results of Cohen and Olshever (2013), Matthew (2003), and Macgowan (2000) who indicated the pivotal role IASWG plays in determining a set of criteria that social workers can adopt in their engagement with groups using evidence-based social group work. More, they stressed the need to apply EBP in social work by means of providing students and social workers with the values, skills and knowledge meant to identify and assess research evidence relevant to their professional practice. Further, they highlighted the significance of developing scales to help workers evaluate EB group work while handling client groups.

\section{Discussion:}

The research concluded a set of general results as follows:

1) Results related to the Cognitive Requirements for Evidence-based social group work:

- Knowledge related to advanced group work.

- Knowledge related to how to handle various technological means to communicate with patient groups.

- Knowledge related to how to assess evidence-based social group work.

2) Results related to the Skill Requirements for Evidence-based social group work:

- Skill to apply evidence-based practice phases to group work.

- Skill to identify evidence needed by patient groups.

- Skill to use proper group work with patients.

3) Results related to the Ethical Requirements for Evidence-based social group work: 
- Keeping the information pertaining to patients and their families confidential.

- Adhering to evidence-based social group work requirements when handling patients.

- Committing to a proper standard of practice when handling patients.

- Committing to the profession's ethics when intervening with patient groups.

4) The Barriers social workers encounter concerning applying Evidencebased social group work:

- Lack of training courses meant to develop EB group work.

- Insufficient physical capabilities in hospitals accommodating social workers.

- Lack of professional awareness of the nature of applying EB group work.

5) Recommendations that enable social workers to apply Evidence-based social group work with patient groups:

- Conducting several training courses on evidence-based social group work.

- Providing logistic support for social workers at hospitals.

- Exchanging diverse experiences of EB group work.

\section{A proposed program to identify the requirements for applying Evidence-} based social group work to develop the professional performance of social workers engaging with patient groups

Worth mentioning, the researcher designed the program in hand according to a set of principles as follows:

\section{First: Program Concept:}

Basically, the program constitutes a set of activities that social workers perform with the aim of applying evidence-based practice steps to group work. Notably, these activities and practices are consistent with workers' preferences, potentials and guidance.

Second: Program Bases:

1- Results of previous studies that stressed the significance of evidence-based social group work.

2- Conceptual framework of the social work profession and group work, besides its technical guidelines and techniques.

3- Results of the study in hand.

4- The main objective of the study - to determine the requirements for applying evidence-based social group work.

\section{Third: Program Objective:}

The program targets at achieving a general objective to determine the requirements for applying evidence-based social group work.

\section{Fourth: Program Considerations:}

The researcher meant the program (including its bases, objectives and subobjectives) to involve a set of considerations, namely; 
1- Considering the clarity of the program objective for social workers engaging with patient groups.

2- Considering the feasibility of the program to be in line with the actual practice of social workers and the events society goes through.

3- Considering the consistency and flexibility of the program so that it is commensurate with workers' capabilities.

4- Providing trainee social workers with experience that could contribute to improving their professional performance with patient groups.

5- Considering accuracy when selecting the technical means to be used.

Fifth: Systems of the Program:

- Member system: including social workers engaging with patient groups.

- Objective system: to provide social workers the opportunity to effectively participate in the program implications so that they can develop their professional performance utilizing evidence-based social group work.

- Performance system: represented by faculty members and experts involved in the program to help it work.

- Change maker system: represents the monitor of group interactions among social workers and the maker of the changes occurring to them to achieve the program objectives.

\section{Sixth: Program implications:}

This conceptualization comprises the requirements for applying evidence-based social group work to develop the professional performance of social workers engaging with patient groups. These requirements are divided into:

A) Cognitive requirements: intended to provide social workers engaging with patient groups with a mass of knowledge on evidence-based social group work, namely;

- Knowledge related to the nature of evidence-based social group work.

- Knowledge related to evidence-based social group work steps.

- Knowledge related to evidence type used in the medical setting.

- Knowledge related to how literature can be used in field practice of the medical setting.

- Knowledge related to advanced group work method.

- Knowledge related to the problems patient groups undergo.

- Knowledge related to making proper decisions about determining evidence suitable to patients.

- Knowledge related to handling patient groups in terms of evidence-based social group work.

- Knowledge related to advanced professional practice methods concerning patient groups.

- Knowledge related to the application of technologies to communicate with patient groups.

- Knowledge related to the difficulties in applying adequate evidence to patients. 
- Knowledge related to assessing evidence-based social group work.

B) Skill requirements: intended to provide social workers engaging with patient groups with a set of skills for applying evidence-based social group work, namely;

- Ability to apply EBS group work steps.

- Ability to determine evidence needed by patient groups.

- Ability to take advantage of work team to attain the best results for patient groups.

- Ability to utilize research when dealing with patients.

- Ability to scientifically solve patients' various problems.

- Ability to search for evidence that best fits patients' problems.

- Ability to classify evidence so that it can be reliable when addressing patient groups.

- Ability to utilize hospitals resources for a better patient care.

- Ability to access to the best evidence suitable to patient groups.

- Ability to properly handle group work.

- Ability to assess the outputs of professional intervention with patient groups.

- Ability to follow-up group work outputs using recent scientific techniques.

C) Ethical requirements: intended to provide social workers engaging with patient groups with a set of ethics when applying evidence-based social group work, namely;

- Adhering to evidence-based social group work requirements when handling patients.

- Keeping the information pertaining to patients and their families confidential.

- Social workers' commitment to a proper standard of practice when handling patients.

- Considering patients' cultural backgrounds when professionally addressing their problems.

- Considering the use of therapeutic methods that match patient groups.

- Making professional relationships with patient groups during professional intervention periods.

- Committing to the profession's ethics when intervening with patient groups.

- Committing to providing a perfect health care to patients who receive medication.

- Being unbiased when handling patients.

- Emphasizing the value of collaboration with the hospital staff to provide patients with several services.

- Paying due attention to individual differences among handled patients. 
- Considering patients' rights which are consistent with health issues they undergo.

\section{Seventh: Program strategies:}

- Knowledge Presentation:

In this strategy, miscellaneous knowledge on group work is demonstrated: implementation steps of EBP, quality of evidence applied to patient groups, justifications for adopting this practice, and evaluation manner of this practice.

\section{- Group Interaction:}

Here, social workers are divided into groups in which a specific professional topic is debated. Throughout this process, members exchange supporting and opposing perspectives until the discussion ends with learning about the most acceptable professional views and ideas, constructive interactions regarding advanced professional practice among social workers when performing program activities are developed, which fulfills group cohesion and growth.

- Persuasion:

In this strategy, social workers show their attitudes towards advanced evidence-based social group work.

- Behavior Modification:

This strategy helps social workers modify their behaviors to transfer from standard practice to advanced one and learn how to evaluate it.

- Group experience consolidation:

This strategy aims to boost workers' positive behaviors and attitudes towards the application of evidence-based social group work and foster individual, group and societal responsibility towards patient groups.

\section{- Problem solving:}

This applies to the problems workers are exposed to while doing the diverse tasks included in the program.

\section{Eighth: Program Techniques:}

- Group Discussion:

This technique is used throughout all of the program stages so as to provide social workers with a great deal of knowledge on evidence-based social group work. The debate is administered through a number of methods, particularly intellectual stimulation, idea exchange groups, and knowledge deepening and refinement using perspective analysis.

- Role Play:

This is applied in terms of two approaches: the first comprises advanced group work, evidence-based social group work as well as its evaluation manner, while the other is that matching the standard practice of group work using scientific methods to discriminate between both so that denial and acceptance can be apparently accounted for.

\section{- Lectures and Seminars:}


In this technique, a set of thoughts and items of knowledge are orally presented on a specific topic by a majored expert addressing a group of audience without providing enough space for participation and discussion. Specifically, key talking points may cover topics like evidence-based practice, evidence-based social group work, hierarchy of evidence, and perfect practice.

Ninth: Program Professional Roles:

The researcher listed a number of jobs and roles that social workers are likely to play in the context of this program: a mentor, an assistant, an expert, a mediator, a stimulator, a professional leader, and a planner.

\section{Tenth: Program Evaluation Tools:}

A questionnaire meant for assessing the proposed program is to be applied to social workers engaging with the program. Thus, this helps learn about their attitudes towards it, its benefit for them, the obstacles that interrupt meeting its objectives, and their recommendations to enhance its effectiveness.

\section{Recommendations:}

- Expanding conducting research on the integration of Evidence-Based Practice in Group Work (EBPGW), specifically when intervening with elder groups as a modern trend that provides a set of evidence and documents.

- Incorporating elders in societal programs and projects with the aim of making the best use of their experiences and knowledge.

- Paying due attention to Services Based on Society (SBS) and its role in addressing elders' problems.

- Doing interdisciplinary studies which emphasize lessening depression and anxiety rates among elder groups.

- Passing legislations and laws that stimulate the application of a rapid social service system addressing emergency situations and problems the elders may go through. 


\section{References}

Adams, K., \& et al (2009). Limitations of Evidence-Based Practice for Social Work Education. Unpacking the complexity. Journal of social work education (45), 2.

Alex Gitterman (2013). Evidence-Guided Practice: Integrating the Science and Art of Social Work. journal of contemporary human services 94(2).

ASGW. (2012). Association for Specialists in Group Work: Multicultural and Social Justice Competence Principles for Group Workers. Journal for Specialists in Group Work, (37), 4.

Bond, G.R. (2004). Supported Employment: Evidence for an Evidence-Based Practice. Psychiatric Rehabilitation Journal, 40.

Bond, G. R., Drake, R. E., \& Becker, D. R. (2010). An update on Randomized Controlled Trials of Evidence-Based Supported Employment. Psychiatric Rehabilitation Journal, 31.

Brettle, A., (2020). Implementing Evidence Based Practice : A guide for radiographers. Radiography, (26), 1

Christ, G., \& Stein, G., \& Bosma, H., (2011). Enhancing Social Work Practice Through Evidence-Based Research: Best Practices for Delivering Care to Families. Journal of Pain and Symptom Management, (41), 1.

Cohen, C., \& Olshever, A., (2013). IASWG Standards for Social Work Practice with Groups: Development, Application, and Evolution. Social Work With Groups 36(2-3).

Connolly, M., \& Harms, L., (2014). Social Work: From Theory to Practice. Cambridge University Press, USA.

Cooper, J (2009). Measurement \& Analysis of Behavior Techniques. Chico, Charles, Mexil, Columbus.

Corey, G. (2008). Theory and Practice of Group Counseling. 7ed, Thomson Brooks/Cole, Belmont.

Cournoyer, B. R. (2004). The Evidence-Based Social Work (EBSW) Skills Book. Allyn \& Bacon, Boston.

Craig, Sh., et al (2020). Empowering the team: A social Work Model of Interprofessional collaboration in hospitals, Journal of Interprofessional Education \& Practice, (19), 4.

Daniel, L., (2011). New Trends in Social Work in Health Care. Physiotherapy, (98), 2 
Dorfman, R., (1996). Clinical Social Work: Definition, Practice and Vision. Psychology Press, New York,

Drisko, J., \& Grady, M. (2012). Evidence-Based Practice. New York: Springer

Drumm, K., (2006). The Essential Power of Group Work. Journal Social Work with Groups, (29), 3.

Dziegielewski, S.,(2004). The Changing Face of Health Care Social Work. Springer Publishing Company, USA.

Frederiksen, S., (2019). Hospital Social Workers and Evidence-Based Practice. M. S. W, McMaster University Hamilton.

Gambrill, E. (2007). Views of Evidence-Based Practice: Social Workers' Code of Ethics and Accreditation Standards as Guides for Choice. Journal of Social Work Education, 43.

Gibbs, L. (2003). Evidence-Based Practice for the helping Professions: A Practical Guide with Integrated Multimedia. Brooks/Cole-Thompson Learning, USA.

Gitterman. A., (2014). Social Work: A Profession in Search of Its Identity. Journal of social work education, (50), 4 .

Goodrich, K. M. (2008). Dual Relationships in Group Training. The Journal for Specialists in Group Work, (33), 3.

Gray, J.A. (2001) Evidence Based Health Care: How to Make Health Policy and Management Decisions. 2Ed, Churchill Livingstone, London.

Gumpert, J., \& Black, P., (2006). Ethical Issues in Group Work: What Are They? How Are They Managed? Journal Social Work with Groups, (29), 1 .

Haywood, V.,(2019). Social Workers Guidelines. Oxford University Press, USA.

Heyman, J., \& Congress, E., (2018). Health and Social Work: Practice, Policy, and Research. Springer Publishing Company, USA.

Houser, J., \& Oman, K., (2011). Evidence-Based Practice. Jones \& Bartlett Learning, USA.

Hyde, B., (2013). Mutual Aid Group Work: Social Work Leading the Way to Recovery-Focused Mental Health Practice. Journal Social Work with Groups, (36), 1.

Jane F. Gilgun (2005). The Four Cornerstones of Evidence-Based Practice in Social Work. Research on Social Work Practice, (15) 1.

Jeffrey, M., \& Matthew, O., (2013). Evidence-Based Practice. Research on Social Work Practice, (8), 4.

Karen M. Allen \& William J. Spitzer (2016).Social Work Practice in Healthcare: Advanced Approaches and Emerging Trends. Sage Publication, USA.

Kumar, H., (2013). Social Work and Developmental Issues. Aakar Books, Indian.

Lietz, C., (2007). Strengths-Based Group Practice: Three Case Studies. Journal Social Work with Groups, (30), 2.

Macgowan, M. J. (2008). A guide to Evidence-Based Social Group Work. Oxford University Press, New York. 
Macgowan, M. J. (2012). A Standards-based Inventory of Foundation Competencies in Social Work with Groups. Research on Social Work Practice, (22), 5 .

Macgowan, M. J. (2012). A standards-based inventory of Foundation Competencies in Social Work with Groups. Research on Social Work Practice.

Macgowan, M., \& Hanbidge, A., (2014). Advancing Evidence-based social group work in Community Mental Health Settings "Methods, Challenges, and Opportunities". In Janice L. DeLucia-Waack, Cynthia R. Kalodner, Maria Riva, (2ed) The Handbook of Group Counseling and Psychotherapy. Sage Publication, USA.

Macgowan, M., (2000). Evaluation of a Measure of Engagement for Group Work. Research on Social Work Practice 10(3).

Macgowan. M., (2006). Evidence-Based Social Group Work. Journal of Evidence-Based Social Work 3(1).

Macgowan. M., (2008). A Guide to Evidence-Based Social Group Work. Oxford University Press, USA.

Matthew, O., et al (2003). Teaching Evidence-Based Practice: Toward a New Paradigm for Social Work Education. Research on Social Work Practice 13(2).

McGuire, D., (2006).Attitudes and Barriers to Evidence-Based Practice in Social Work. .University of Houston, ProQuest Dissertations Publishing, 2006.

Merriam-Webster's Collegiate Dictionary (2004). Webster's Dictionary. Lexicon Publications, USA.

NASW (2003). Code of Ethics of the National Association of Social Workers. USA.

Norcross, J. C., \& Lambert, M. J. (2011). Psychotherapy Relationships that work II. Psychotherapy, (48), 1

Norcross, J. C., \& Lambert, M. J. (2011). Evidence-Based therapy Relationships. Oxford University Press, USA.

Pandya, V., (2010). An Evidence Base for Group Work with Older Adults Living in the Community. Social Work With Groups 33(4).

Pollio, D.,(2008). The Evidence-Based Social Group Worker. Journal Social Work with Groups, (25), 4.

Quinn, A., \& Shera, W., (2009). Evidence-Based Practice in Group Work with Incarcerated Youth. International Journal of Law and Psychiatry, 32.

Regehr, C., Stern, S., \& Shlonsky, A. (2007). Operationalizing Evidence-Based Practice: the development of an Institute for Evidence-Based Social Work. Research on Social Work Practice, (17).

Rosen, A. (2003). Evidence-Based Social Work Practice: Challenges and Promise. Social Work Research, 27. 
Rubin, A. \& Parrish, D. (2009). Development and Validation of the EvidenceBased Practice Process Assessment Scale. Research on Social Work Practice.

Sackett, D. L., Rosenberg,W. M. C., Gray, J. A. M., Haynes, R. B., \& Richardson,W. S. (1996). Evidence based medicine: What it is and what it isn't: It's about integrating individual clinical expertise and the best external evidence. British Medical Journal, 312, 71-72.

Smith, C., Cohen-Callow, A., Harnek Hall, D., \& Hayward, A. (2007). Impact of a Foundation Level MSW Research Course on Students' Critical Appraisal Skills. Journal of Social Work Education, 43.

Spensberger, F., (2019). How to Teach Evidence-Based Practice in Social Work: A Systematic Review. Research on Social Work Practice, (12), 2.

Stevenson, A., (2010). Oxford Dictionary of English. Oxford University Press, USA.

Straus, S. E., Richardson, W. S., Glasziou, P., \& Haynes, R. B. (2005). EvidenceBased Medicine: How to practice and teach EBM. 3ed, Edinburgh: Churchill Livingstone.

Straus, S. E., Richardson, W. S., Glasziou, P., \& Haynes, R. B. (2005). EvidenceBased Medicine: How to practice and teach EBM. 3ed, Edinburgh: Elsevier Churchill Livingstone.

Tabachnick, B. G., \& Fidell, L. S. (2007). Using Multivariate Statistics. 5ed, Pearson Education, Boston.S

Terry, F., (2015). Harmony and Social Work Practice, International Encyclopedia of the Social \& Behavioral Sciences, 529-535

Weller, B., (2015). Applying Evidence-Based Practice in Group Work at an Alternative High School. Journal Social Work With Groups, 38(2).

Wike, T. L., et al (2014). Evidence-based practice in social work: Challenges and opportunities for clinicians and organizations. Clinical Social Work Journal, 42(2).

Worsley, A., et al (2013). Key Concepts in Social Work Practice. Sage Publication, USA,

Yuill, Ch., \& Gibson, A.,(2017). Sociology for Social Work: An Introduction. Sage Publication, USA. 